\title{
Costs and cost-effectiveness of community health workers: evidence from a literature review
}

\author{
Kelsey Vaughan ${ }^{1 *}$, Maryse C Kok' ${ }^{1}$ Sophie Witter ${ }^{2}$ and Marjolein Dieleman ${ }^{1}$
}

\begin{abstract}
Objective: This study sought to synthesize and critically review evidence on costs and cost-effectiveness of community health worker (CHW) programmes in low- and middle-income countries (LMICs) to inform policy dialogue around their role in health systems.

Methods: From a larger systematic review on effectiveness and factors influencing performance of close-tocommunity providers, complemented by a supplementary search in PubMed, we did an exploratory review of a subset of papers (32 published primary studies and 4 reviews from the period January 2003-July 2015) about the costs and cost-effectiveness of CHWs. Studies were assessed using a data extraction matrix including methodological approach and findings.

Results: Existing evidence suggests that, compared with standard care, using CHWs in health programmes can be a cost-effective intervention in LMICs, particularly for tuberculosis, but also - although evidence is weaker - in other areas such as reproductive, maternal, newborn and child health (RMNCH) and malaria.

Conclusion: Notwithstanding important caveats about the heterogeneity of the studies and their methodological limitations, findings reinforce the hypothesis that CHWs may represent, in some settings, a cost-effective approach for the delivery of essential health services. The less conclusive evidence about the cost-effectiveness of CHWs in other areas may reflect that these areas have been evaluated less (and less rigorously) than others, rather than an actual difference in cost-effectiveness in the various service delivery areas or interventions. Methodologically, areas for further development include how to properly assess costs from a societal perspective rather than just through the lens of the cost to government and accounting for non-tangible costs and non-health benefits commonly associated with CHWs.
\end{abstract}

Keywords: Community health workers, Cost-effectiveness, Costs, Literature review

\section{Introduction}

In recent years, community health workers (CHWs) have received renewed attention in light of critical shortages in the health workforce and emphasis on strengthening primary healthcare systems for achieving global health goals [1-4]. CHWs are generally assumed to be a less expensive alternative compared with other cadres of health workers, notably with regard to salary and incentives as well as training costs. In parallel, more and more

\footnotetext{
* Correspondence: kvaughan@gmail.com

'Royal Tropical Institute (KIT), P.O. Box 95001, 1090 HA Amsterdam, The Netherlands

Full list of author information is available at the end of the article
}

evidence has accumulated in recent years on the effectiveness of CHWs in delivery of essential health services in low- and middle-income countries (LMICs) [5-7]. However, studies assessing the costs and/or costeffectiveness of CHW programmes are limited due both to data and methodological problems $[1,8,9]$. Therefore, we conducted an exploratory literature review to:

1. provide an overview of what is globally known about CHW' costs and cost-effectiveness

2. identify methodologies and elements of costs, effects and cost-effectiveness included in and excluded from studies to date

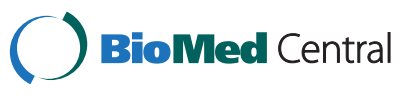

(c) 2015 Vaughan et al. Open Access This article is distributed under the terms of the Creative Commons Attribution 4.0 International License (http://creativecommons.org/licenses/by/4.0/), which permits unrestricted use, distribution, and reproduction in any medium, provided you give appropriate credit to the original author(s) and the source, provide a link to the Creative Commons license, and indicate if changes were made. The Creative Commons Public Domain Dedication waiver (http://creativecommons.org/publicdomain/zero/1.0/) applies to the data made available in this article, unless otherwise stated. 
3. discuss appropriate methodologies for evaluating the costs and cost-effectiveness of CHWs.

As this was an exploratory review, no estimates in monetary terms (dollar values) are presented. Nonetheless, the overall conclusions about the costs and costeffectiveness of CHWs will serve to inform policy dialogue around the role of CHWs in health systems, and findings about methodologies will encourage researchers to properly assess the costs and costeffectiveness of such programmes.

\section{Methods}

\section{Definitions}

For the purpose of this literature review, the definition of CHW that we used is the following [6]: "Any health worker carrying out functions related to health care delivery; trained in some way in the context of the intervention, and having no formal professional or paraprofessional certificate or degree in tertiary education". Costs are defined as the resources, either expended or foregone, associated with implementing a health programme or treatment. Costeffectiveness as a study type is defined as "one form of economic evaluation where both the costs and consequences of health programmes or treatments are examined" [10]. When comparing two programmes or scenarios, intervention A is said to be more "cost-effective" than intervention $B$ when programme cost per unit effectiveness for $A$ is less than for B. "Cost-effective" may also refer to a comparison with a threshold or benchmark. In the rest of the paper, we refer to consequences as benefits or effectiveness, defined as the change in desired outcome due to the intervention or programme. We refer to final patient outcomes (change in health status and/or well-being) wherever possible; where not available, measurable intermediate patient outcomes (for example, number of patients visited and number of visits conducted) and measurable CHW provider outcomes (for example, improved CHW productivity) are used.

\section{Search strategy}

We used the search results from a larger, systematic review on factors influencing performance of close-tocommunity providers, which included searching the EMBASE, PubMED, Cochrane, CINAHL, POPLINE and NHS-EED databases for the period January 2003 to April 2013 [2] as well as a manual search of reference lists of all papers. This broader review included quantitative, qualitative and mixed method studies, all in English, about CHWs working in promotional, preventive or curative primary healthcare in LMICs. From that search, we extracted costing studies, studies that assessed the costs and effects of a single CHW intervention and economic evaluations assessing the costs and benefits of at least two CHW interventions. We conducted an additional search in PubMed for articles published during the same period to verify the existence of any further relevant papers (see Table 1); this search was later updated to include articles published from May 2013 to July 2015. The search strategy is summarized in Figure 1 while the full search strategy is presented elsewhere [2].

\section{Review approach}

Three reviewers jointly developed two separate data extraction matrices. The first matrix captured the study or model's overall methodological approach as well as specifics regarding how costs, effects and cost-effectiveness of the CHW programme were assessed. The overall methodological approach included study design, perspective, time horizon, discounting, year of costing and currency, intervention and comparator(s), setting, scenarios, sensitivity analysis and software. In terms of costs, the data extraction form captured programme (training, recurrent, capital and overhead/indirect) and patient costs, costs averted, how costs are reported and data sources. A review of the outcomes included both patient and provider outcomes and was defined as final patient outcomes (change in health status and/or wellbeing), measurable intermediate outcomes (for example, number of patients visited and number of visits conducted)

Table 1 Search details of the supplementary search

\begin{tabular}{|c|c|c|c|}
\hline PubMed & & $\begin{array}{l}\text { Results } 16 \text { July } 2013 \\
\text { (for January } 2003 \text { to } \\
\text { April 2013) }\end{array}$ & $\begin{array}{l}\text { Results } 1 \text { August } \\
2015 \text { (for May } 2013 \\
\text { to July 2015) }\end{array}$ \\
\hline$\# 1$ & $\begin{array}{l}\text { "community health worker" OR "community health workers" OR " } \\
\text { community health workers"[MeSH] }\end{array}$ & 1441 & 916 \\
\hline$\# 2$ & $\begin{array}{l}\text { "health economics" OR "economics, medical"[MeSH] OR "economic } \\
\text { evaluation" OR "health care costs" OR "health resource allocation" OR } \\
\text { "health resource utilization" OR costs OR "costs and cost analysis"[MeSH] } \\
\text { OR "cost analysis" OR "cost-benefit analysis"[MeSH] OR "cost effectiveness" } \\
\text { OR "cost effective" OR "health care costs" OR "cost benefit analysis" OR } \\
\text { "cost-benefit analysis"[MeSH] OR costly OR costing OR price OR prices OR } \\
\text { expenditure OR "health expenditures"[MeSH] OR "value for money" OR } \\
\text { budget OR budgets OR DALYs OR QALYs OR "quality-adjusted life years"[MeSH] }\end{array}$ & 96561 & 64724 \\
\hline \#1 AND \#2 & & 134 & 113 \\
\hline
\end{tabular}




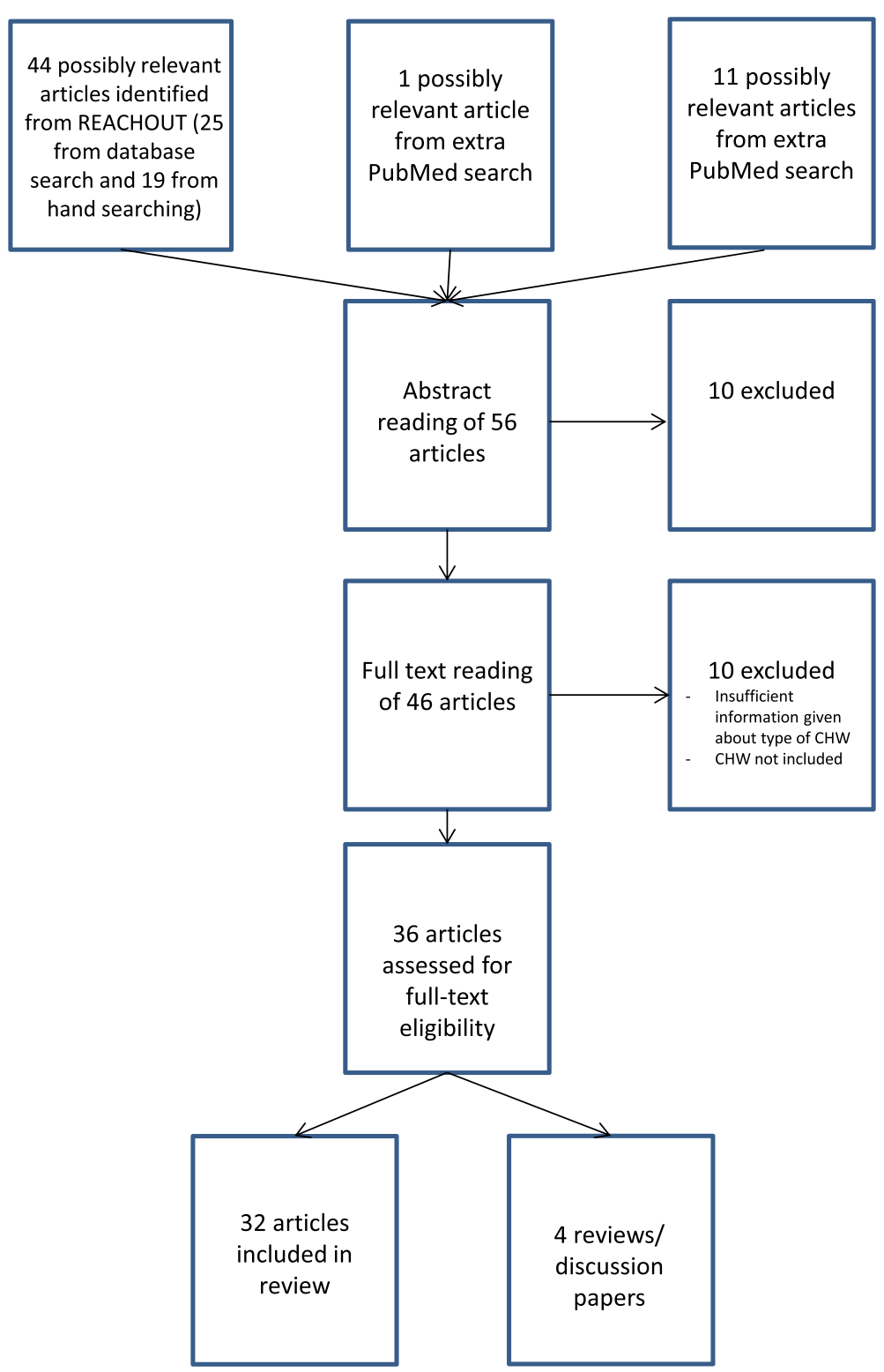

Figure 1 Flow chart of search strategy.

and measurable CHW provider outcomes (for example, improved CHW productivity). The cost-effectiveness measure was also indicated. Although elements of quality were included in our data extraction and analysis, our review did not exclude studies based on a full assessment of study quality, because of the high diversity in types and focuses of the studies.

The second matrix captured the study or model's findings in terms of costs, outcomes and cost-effectiveness. Findings from any sensitivity analyses were also extracted. Systematic reviews were summarized in terms of main CHW-related findings.

We piloted the abstraction process by having the three reviewers jointly analyse and discuss one article and then discuss as a team questions that arose during data extraction. All papers were then read and abstracted by a single reviewer. Each reviewer completed the data extraction matrix separately, and review results were compiled into a single matrix for analysis. Analysis was done by summarizing and discussing the data within the team, following the categories as presented above. For an overview of the review approach, see Figure 2.

\section{Results}

\section{Search results}

The search strategy resulted in 32 individual articles about 31 studies being fully reviewed using the data extraction matrix and four review/discussion papers summarized. 


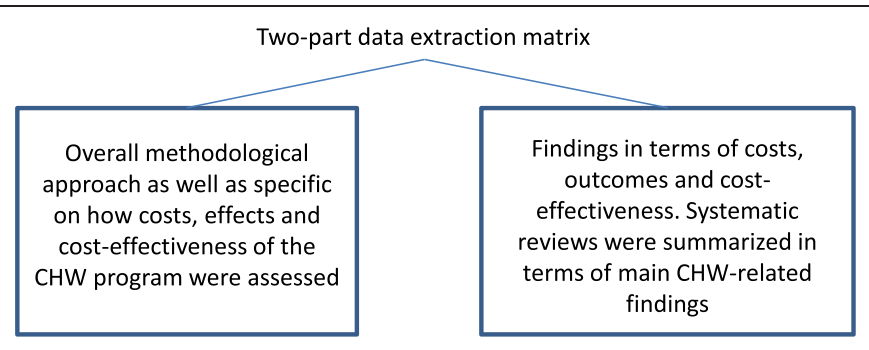

\footnotetext{
- Three reviewers jointly filled in the matrix for one study and discussed questions that arose during data extraction; based on this, the matrix was slightly adjusted.

- All papers were then read by one of three reviewers. Each reviewer completed the data extraction matrix.

- Analysis was done by summarizing and discussing the data within the team, following the categories of the matrix.
}

Figure 2 Review approach.

Table 2 presents an overview of the methodological characteristics of included studies, while Table 3 outlines the included studies with their location, type of $\mathrm{CHW}$, intervention description, perspective, cost components included, and any assessment regarding cost-effectiveness. These aspects of the included studies are discussed below.

\section{Types of CHWs, setting and health priorities}

In terms of types of CHWs included, the assessed articles included a range of $\mathrm{CHW}$ types and nomenclatures (see Table 3). Twelve out of 32 articles did not specifically discuss training or the duration was not specified; where mentioned, however, all CHWs received some type of training ranging from 1 day to 1 year [11-24].

The studies reported a variety of geographical areas and settings. Eighteen articles presented results from sub-Saharan Africa, nine from Asia and three from Latin America. Two articles included various countries in Africa (see Table 3). A number of different settings were included: home $(n=10)$, villages or general community $(n=7)$, health facility or health centre $(n=3)$ and workplace $(n=1)$. One study reviewed the experience of CHWs and mobile health (m-health). Several studies included CHWs operating in various settings $(n=4)$, while seven studies did not specify the exact setting.

Health priority areas addressed by CHWs included reproductive, maternal, newborn and child health (RMNCH, $n=13$, including two reviews), tuberculosis (TB) $(n=6)$, malaria $(n=7)$ and a range of other disease areas or multiple areas including (problems regarding) hypertension, diarrhoea, malnutrition, pneumonia, common mental disorders and a range of primary care services $(n=7)$. CHWs working in $\mathrm{RMNCH}$ performed a wide variety of activities including basic curative activities, counselling and health promotion, referrals, prenatal care and support during home deliveries. CHWs involved in TB and malaria mainly administered directly observed therapy (DOT) of TB medicines and dispensed drugs. CHWs working in other disease areas were involved in different types of activities, ranging from health education and promotion, screening, diagnosis and management of some conditions to referrals.

\section{Costs}

In terms of programme costs included, all but six studies $[12,13,17,22,25,26]$ clearly included the value of the CHWs' time spent (either compensated or, for

Table 2 Methodological characteristics of included studies

\begin{tabular}{|c|c|}
\hline $\begin{array}{l}\text { Methodological } \\
\text { area }\end{array}$ & Details of included studies \\
\hline \multirow[t]{3}{*}{ Study type } & $\begin{array}{l}17 \text { economic evaluations, often comparing CHWs } \\
\text { with facility-based practice }\end{array}$ \\
\hline & $\begin{array}{l}5 \text { articles looked at the costs and benefits of a } \\
\text { single intervention or programme }\end{array}$ \\
\hline & 10 articles included cost data only \\
\hline \multirow[t]{3}{*}{ Perspective } & Provider or health system perspectives ( $n=15$ ) \\
\hline & Wider societal perspectives $(n=14)$ \\
\hline & Three studies did not specify the perspective taken \\
\hline \multirow[t]{2}{*}{ Time horizon } & $\begin{array}{l}\text { Only four studies included a time horizon greater } \\
\text { than } 1 \text { year }\end{array}$ \\
\hline & $\begin{array}{l}\text { The others }(n=28) \text { either did not specify a time } \\
\text { horizon or used } 1 \text { year }\end{array}$ \\
\hline \multirow[t]{2}{*}{$\begin{array}{l}\text { Sensitivity } \\
\text { analysis }\end{array}$} & $\begin{array}{l}17 \text { studies performed a sensitivity analysis, the } \\
\text { majority }(n=10) \text { using a one-way or univariate } \\
\text { analysis }\end{array}$ \\
\hline & $\begin{array}{l}\text { Variables used in the sensitivity analysis include } \\
\text { the following: unit costs and quantities of provider } \\
\text { and patient cost items, assumptions about training } \\
\text { (varying the intensity, excluding one type of } \\
\text { training and varying the cost of the training), } \\
\text { varying discount and exchange rates, administrative } \\
\text { support, useful life of capital items and effectiveness } \\
\text { data, including CHW salaries, including inclusion of } \\
\text { life years saved and deaths averted }\end{array}$ \\
\hline
\end{tabular}


Table 3 Summary of key methodological points and cost and cost-effectiveness results of included studies

\begin{tabular}{lllll}
\hline Study Country & Type of CHW & Description & $\begin{array}{l}\text { Type of study and } \\
\text { perspective }\end{array}$ & \begin{tabular}{l} 
Programme costs included \\
\cline { 3 - 4 }
\end{tabular}
\end{tabular}

\section{Maternal health}

Alem et al. Bangladesh CHWs 2012 [27]

Sutherland India

and Bishai.

Village health

2009 [39]

Simulation study on materna

health: prevention of PPH

Cost-effectiveness study

from a provider

perspective.

Simulation study on

prevention of PPH by VHWs.

Cost-effectiveness study from a provider

perspective.
No

an

leads to foregone health

services as well as recruitment and training of replacements. With an additional investment double the initial investment per CHW, the organization reduces dropout, can make additional cost savings (not recruiting and training a replacement) and fewer services are foregone in the community.

Misoprostol prevention and treatment provided by VHWs are both more cost-effective than standard care (although standard care is not defined). standard care is not defined more cost-effective than prevention in terms of cost per life saved.

Misoprostol prevention and treatment provided by VHWs are both more cost-effective than standard care (although standard care is not defined). Treatment is significantly more cost-effective than prevention in terms of cost per life saved.

Provision of injectable contraceptives by CHWs can be done at low cost when added to an existing community-based distribution package.

\section{Yes}

Yes lay health workers could
Economic evaluation with provider perspective alongside RCT
Women groups facilitated by provide a cost-effective way of reducing neonatal deaths compared to current practice. 
Table 3 Summary of key methodological points and cost and cost-effectiveness results of included studies (Continued)

\begin{tabular}{|c|c|c|c|c|c|c|c|c|c|c|}
\hline $\begin{array}{l}\text { Chola et al. } \\
2011[28]\end{array}$ & Uganda & Peer supporters & $\begin{array}{l}\text { Breastfeeding intervention } \\
\text { delivered by local women } \\
\text { trained as peer supporters. }\end{array}$ & $\begin{array}{l}\text { Costing study from } \\
\text { a local provider } \\
\text { perspective }\end{array}$ & Yes & Yes & Yes & Yes & No & $\begin{array}{l}\text { The use of local women } \\
\text { trained as peer supporters to } \\
\text { individually counsel women } \\
\text { about exclusive breast feeding } \\
\text { can be implemented in sub- } \\
\text { Saharan Africa at a "sustainable } \\
\text { cost". }\end{array}$ \\
\hline $\begin{array}{l}\text { Sabin et al. } \\
2012 \text { [38] }\end{array}$ & Zambia & $\begin{array}{l}\text { Traditional birth } \\
\text { attendants (TBAs) }\end{array}$ & $\begin{array}{l}\text { Neonatal healthcare delivered } \\
\text { by trained TBAs. }\end{array}$ & $\begin{array}{l}\text { Costing and cost- } \\
\text { effectiveness study } \\
\text { alongside RCT; financial } \\
\text { analysis based on trial } \\
\text { costs only then expanded } \\
\text { to intervention economic } \\
\text { costs from societal } \\
\text { perspective }\end{array}$ & Yes & No & Yes & No & No & $\begin{array}{l}\text { The strategy of using trained } \\
\text { TBAs to perform the neonatal } \\
\text { resuscitation protocol (NRP) } \\
\text { and antibiotics with facilitated } \\
\text { referral to a health centre } \\
\text { (AFR) to reduce neonatal } \\
\text { mortality was found to be } \\
\text { highly cost-effective as } \\
\text { compared to GDP per capita } \\
\text { and per WHO guidelines in } \\
\text { Zambia. }\end{array}$ \\
\hline \multicolumn{11}{|l|}{ Child health } \\
\hline $\begin{array}{l}\text { Fiedler } 2003 \\
{[16]}\end{array}$ & Honduras & Monitors/CHWs & $\begin{array}{l}\text { Growth monitoring of children } \\
\text { under two by CHWs. The CHW } \\
\text { treats and refers children under } \\
\text { five to health services. }\end{array}$ & $\begin{array}{l}\text { Costing study from a } \\
\text { health service } \\
\text { perspective. }\end{array}$ & Yes & Unclear & Yes & No & No & $\begin{array}{l}\text { CHW programme cost } 11 \% \\
\text { of the facility-based alternative } \\
\text { while saving outpatient visits } \\
\text { and costs. }\end{array}$ \\
\hline $\begin{array}{l}\text { Fiedler et al. } \\
2008[17]\end{array}$ & Honduras & Monitors/CHWs & $\begin{array}{l}\text { Growth monitoring of children } \\
\text { under two by CHWs. The CHW } \\
\text { treats and refers children under } \\
\text { five to health services. }\end{array}$ & $\begin{array}{l}\text { Costing study from a } \\
\text { health service } \\
\text { perspective }\end{array}$ & Yes & Unclear & Yes & No & No & $\begin{array}{l}\text { CHW programme cost } 11 \% \\
\text { of the facility-based alternative } \\
\text { while saving outpatient visits } \\
\text { and costs. }\end{array}$ \\
\hline $\begin{array}{l}\text { Nonvignon } \\
\text { et al. } 2012 \\
\text { [19] }\end{array}$ & Ghana & CHWs & $\begin{array}{l}\text { CHW home management of } \\
\text { malaria using two different drugs, } \\
\text { by voluntary community-based } \\
\text { agents in Ghana. }\end{array}$ & $\begin{array}{l}\text { Cost-effectiveness study } \\
\text { with a societal } \\
\text { perspective }\end{array}$ & Unclear & Yes & Yes & Unclear & Unclear & $\begin{array}{l}\text { Home management of under- } \\
\text { five fevers by trained, unpaid } \\
\text { community volunteers through } \\
\text { diagnosis and dispensing of } \\
\text { antimalarials and/or antibiotics } \\
\text { was found to be a cost- } \\
\text { effective strategy (in terms } \\
\text { of cost per DALY averted } \\
\text { compared with threshold } \\
\text { recommended by WHO) for } \\
\text { reducing under-five mortality } \\
\text { in this setting. }\end{array}$ \\
\hline $\begin{array}{l}\text { Prinja et al. } \\
2013 \text { [36] }\end{array}$ & India & $\begin{array}{l}\text { Auxiliary nurse } \\
\text { midwives (ANM), } \\
\text { anganwadi workers } \\
\text { (AWW) and } \\
\text { accredited social } \\
\text { health activists } \\
\text { (ASHA) }\end{array}$ & $\begin{array}{l}\text { Comparison of costs of } \\
\text { integrated management of } \\
\text { neonatal and childhood } \\
\text { illnesses (IMNCI) and no IMNCl. }\end{array}$ & $\begin{array}{l}\text { Economic evaluation } \\
\text { from a programme } \\
\text { perspective nested in } \\
\text { an effectiveness trial }\end{array}$ & Yes & Yes & Yes & Yes & No & $\begin{array}{l}\text { Implementation of IMNCI } \\
\text { imposes additional costs to } \\
\text { the health system; cost- } \\
\text { effectiveness needs to be } \\
\text { assessed in a comprehensive } \\
\text { economic evaluation. }\end{array}$ \\
\hline
\end{tabular}
政 five to health services. under two by CHWs. The CHW five to health services: by voluntary community-based agents in Ghana.

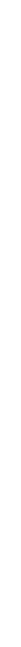


Table 3 Summary of key methodological points and cost and cost-effectiveness results of included studies (Continued)

\begin{tabular}{|c|c|c|c|c|c|c|c|c|c|c|}
\hline $\begin{array}{l}\text { Puett et al. } \\
2013 \text { [37] }\end{array}$ & Bangladesh & CHWs & $\begin{array}{l}\text { Comparison of home } \\
\text { management of severe acute } \\
\text { nutrition versus facility-based } \\
\text { inpatient treatment. }\end{array}$ & $\begin{array}{l}\text { Cos-effectiveness study } \\
\text { from a societal perspective }\end{array}$ & Yes & Yes & Yes & Yes & Yes & $\begin{array}{l}\text { Treatment of severe acute } \\
\text { malnutrition by CHWs is } \\
\text { highly cost-effective compared } \\
\text { to facility-based treatment. }\end{array}$ \\
\hline $\begin{array}{l}\text { Tozan et al. } \\
2010 \text { [23] }\end{array}$ & Africa & CHWs & $\begin{array}{l}\text { A community-based pre- } \\
\text { referral artesunate treatment } \\
\text { and referral programme by } \\
\text { CHWs for children suspected } \\
\text { to have severe malaria in areas } \\
\text { with poor access to formal } \\
\text { healthcare in rural Africa. }\end{array}$ & $\begin{array}{l}\text { Cost and effects of } \\
\text { single intervention from } \\
\text { a provider perspective }\end{array}$ & Unclear & No & Yes & No & No & $\begin{array}{l}\text { Pre-referral artesunate } \\
\text { treatment delivered by } \\
\text { CHWs is a cost-effective } \\
\text { (as compared to GDP } \\
\text { per capita and per WHO } \\
\text { guidelines), life-saving } \\
\text { intervention, which can } \\
\text { substantially improve the } \\
\text { management of severe } \\
\text { childhood malaria in rural } \\
\text { African settings. }\end{array}$ \\
\hline \multicolumn{11}{|l|}{ Tuberculosis } \\
\hline $\begin{array}{l}\text { Clarke et al. } \\
2006[14]\end{array}$ & South Africa & $\begin{array}{l}\text { Lay health workers } \\
\text { (LHWs) }\end{array}$ & $\begin{array}{l}\text { Tuberculosis treatment } \\
\text { adherence and counselling by } \\
\text { trained LHWs on farms. }\end{array}$ & $\begin{array}{l}\text { Cost-effectiveness } \\
\text { analysis alongside RCT } \\
\text { from a health district } \\
\text { perspective }\end{array}$ & No & Unclear & Yes & No & No & $\begin{array}{l}\text { Costs to public budgets can } \\
\text { be substantially reduced } \\
\text { while maintaining or } \\
\text { improving case detection } \\
\text { and treatment outcomes, by } \\
\text { using farm-based LHWs. }\end{array}$ \\
\hline $\begin{array}{l}\text { Datiko and } \\
\text { Lindtjørn } \\
2010[15]\end{array}$ & Ethiopia & $\begin{array}{l}\text { Health extension } \\
\text { workers (HEWs) }\end{array}$ & $\begin{array}{l}\text { HEWs administered DOT for } \\
2 \text { months during intensive } \\
\text { phase at health post, gave out } \\
\text { drugs on monthly basis during } \\
\text { continuation phase. }\end{array}$ & $\begin{array}{l}\text { Cost and cost- } \\
\text { effectiveness as part of } \\
\text { randomized trial from a } \\
\text { societal perspective }\end{array}$ & No & Yes & Yes & Yes & Yes & $\begin{array}{l}\text { Involving HEWs in TB } \\
\text { treatment is cost-effective } \\
\text { alternative to health facility } \\
\text { delivery. }\end{array}$ \\
\hline $\begin{array}{l}\text { Floyd et al. } \\
2003[18]\end{array}$ & Malawi & Guardians & $\begin{array}{l}\text { Out-patient DOT at health } \\
\text { facilities (by CHW) or by } \\
\text { community member guardian } \\
\text { (only new smear-negative } \\
\text { patients), handing out drugs in } \\
\text { an urban setting. }\end{array}$ & $\begin{array}{l}\text { Cost and cost- } \\
\text { effectiveness from a } \\
\text { societal perspective }\end{array}$ & No & Yes & Yes & Yes & Yes & $\begin{array}{l}\text { When new smear-positive } \\
\text { and smear-negative patients } \\
\text { were considered together, } \\
\text { the new strategies were } \\
\text { associated with a } 50 \% \\
\text { reduction in total annual } \\
\text { costs compared with the } \\
\text { strategy used until end of } \\
\text { October } 1997 \text { which did not } \\
\text { require any direct observation } \\
\text { of treatment. }\end{array}$ \\
\hline $\begin{array}{l}\text { Okello et al. } \\
2003 \text { [20] }\end{array}$ & Uganda & $\begin{array}{l}\text { Community } \\
\text { volunteers }\end{array}$ & $\begin{array}{l}\text { DOT at community level by } \\
\text { village-based volunteers. }\end{array}$ & $\begin{array}{l}\text { Cost-effectiveness study } \\
\text { from a societal } \\
\text { perspective }\end{array}$ & Yes & No & Yes & Yes & Yes & $\begin{array}{l}\text { Findings suggest there is a } \\
\text { strong economic case for } \\
\text { replacing hospital admission } \\
\text { for the first } 2 \text { months of } \\
\text { treatment followed by } \\
6 \text { months of daily } \\
\text { unsupervised outpatient } \\
\text { treatment with community- } \\
\text { based care in Uganda, } \\
\text { provided it is accompanied }\end{array}$ \\
\hline
\end{tabular}




\begin{tabular}{|c|c|c|c|}
\hline $\begin{array}{l}\text { Prado et al. } \\
2011 \text { [21] }\end{array}$ & Brazil & $\begin{array}{l}\text { Trained guardians } \\
\text { and CHWs }\end{array}$ & TB care in an urban setting. \\
\hline $\begin{array}{l}\text { Sinanovic } \\
\text { et al. } 2003 \\
\text { [22] }\end{array}$ & South Africa & CHWs/LHWs & $\begin{array}{l}\text { New smear-positive pulmonary } \\
\text { and retreatment patients re } \\
\text { ceiving treatment for TB by } \\
\text { CHWs/LHWs. }\end{array}$ \\
\hline \multicolumn{4}{|l|}{ Malaria } \\
\hline $\begin{array}{l}\text { Chanda } \\
\text { et al. } 2011 \\
\text { [13] }\end{array}$ & Zambia & CHWs & $\begin{array}{l}\text { CHWs using rapid diagnostic } \\
\text { test for malaria in Zambia. } \\
\text { Complicated malaria cases and } \\
\text { non-malaria febrile cases were } \\
\text { referred to the nearest health } \\
\text { facility for further management. } \\
\text { Uncomplicated malaria cases } \\
\text { were treated by the CHW using } \\
\text { artemisinin-based combination } \\
\text { therapy (ACT). }\end{array}$ \\
\hline
\end{tabular}

Community-based Community-based volunteers

[29]

Hamainza Zambia
et al. 2014

et al. 2014

[24]

Mbonye Uganda
et al. 2008

[31]

Onwujekwe Nigeria et al. 2007

[41] volunteers

$y$-based volunteers delivered three different intermittent preventive children (IPTC) drug regimens to children aged 3-59 months.

CHWs

Home-based case detection and treatment of malaria with rapid diagnostic tests (RDTs) by CHWs versus facility care.

\section{TBAs, drug-shop Directly observed sulfadoxine-} vendors, community pyrimethamine (SP) therapy reproductive delivered by trained commu health workers and nity resource persons to adolescent peer pregnant women through mobilizers home visits during second and third trimester in a rural setting

CHWs

mers conducted treatment of presumptive malaria in
Cost-effectiveness study from a societal perspective

\section{Economic evaluation} from a societal

perspective as part of a prospective cohort study

Cost-effectiveness study from a provider

perspective uncomplicated adults and children.

Economic evaluation alongside RCT from societal perspective

Costing study from a programme perspective study.

Cost-effectiveness study from both provider and patient perspectives

Costs and benefits of a single intervention from both provider and

community perspectives by strong investment in activities such as training community mobilization and programme supervision.

Guardian-supervised DOT is an attractive option to complement CHW-s upervised DOT.

Community-based care is a cost-effective strategy for TB treatment compared with the facility alternative.

Home management of uncomplicated malaria by CHWs was 36\% more costeffective than the standard of care at health facility level in this setting. alongside a longitudina

Yes

Yes Yes

Yes

Yes

Yes Unclear Yes Unclear Unclear


Table 3 Summary of key methodological points and cost and cost-effectiveness results of included studies (Continued)

$\begin{array}{ll}\begin{array}{l}\text { Patouillard Ghana } \quad \text { VHWs } \\ \text { et al. 2011 }\end{array} & \begin{array}{l}\text { VHWS dispensed IPTc during } \\ \text { three consecutive scheduled } \\ \text { [33] }\end{array} \\ & \begin{array}{l}\text { days from a central point of } \\ \text { each village. }\end{array}\end{array}$

Other or multiple disease areas

Bowser Mozambique CHWs et al. 2015

[34]

Buttorf et al. India

LHWS $2012[12]$

WW
This study compares CHWs visiting patients with

uncontrolled hypertension two times a year with undefined usual care.

Jafar et al. Pakistan CHWs 2011 [30]

Mahmud Malawi CHWs
et al. 2010

CHWs provided advice at three monthly intervals on the importance of physical activity, diet and smoking cessation.

CHWs using text messages
Multi-year comparison of costs and benefits of delivery by

CHWs of specialized targeted package of primary care interventions including family planning, maternal health, malaria, diarrhoea, pneumonia, LHWs/counsellors counselled on mental disorders. delivered a variety of services including requesting medication deliveries, notifying patient deaths, sending appointment reminders,

monitoring treatment adherence for TB DOTS and ART, queries and more.
Costing study from a provider perspective alongside community randomized trial

Cost-effectiveness study taking a programme

perspective

Economic evaluation from a societal perspective alongside $\mathrm{RCT}$

Cost-utility study using a Markov model,

perspective undefined

Cost-effectiveness study from a societal perspective alongside RCT

Costing study with unspecified perspective (seems to be hospital) providing timely, appropriate treatment of malaria in rural areas.

Delivery of IPT for children by VHWs is less costly then delivery by nurses working at outpatient departments or EPI outreach.

Using CHWs to deliver a range of primary care services can be less costly than other community-based programmes.

LHW intervention resulted in cost savings from both a provider and patient perspective and achieved the same outcomes, making it more cost-effective than standard care at public primary care facilities.

The intervention is costsaving, with the life cost being less than the annual cost due to reductions in non-fatal cardiovascular disease-related events.

A combined intervention of HHE plus training of general practitioners to control high blood pressure is the most cost-effective solution as compared with other options.

m-health intervention

delivered by CHWs resulted in both professional worker time and monetary savings compared with previous practice (a CHW programme without the m-health

intervention). 
Table 3 Summary of key methodological points and cost and cost-effectiveness results of included studies (Continued)

\begin{tabular}{|c|c|c|c|c|c|c|c|c|c|c|}
\hline $\begin{array}{l}\text { McCord } \\
\text { et al. } 2013 \\
\text { [32] }\end{array}$ & $\begin{array}{l}\text { Sub-Saharan } \\
\text { Africa }\end{array}$ & CHWs & $\begin{array}{l}\text { Various (diarrhoea, malaria, } \\
\text { malnutrition, TB screening, } \\
\text { pneumonia, management of } \\
\text { pregnancy and health } \\
\text { promotion). }\end{array}$ & $\begin{array}{l}\text { Costing study from } \\
\text { unspecified perspective } \\
\text { (seems to be programme) }\end{array}$ & Yes & Yes & Yes & Yes & No & $\begin{array}{l}\text { Comprehensive CHW } \\
\text { subsystems can be deployed } \\
\text { across sub-Saharan Africa at } \\
\text { a cost that is modest com } \\
\text { pared with project costs of } \\
\text { primary healthcare system. }\end{array}$ \\
\hline $\begin{array}{l}\text { Prinja et al. } \\
2014 \text { [35] }\end{array}$ & India & $\begin{array}{l}\text { Auxiliary nurse } \\
\text { midwives (ANMs), } \\
\text { multi-purpose } \\
\text { health workers } \\
\text { (MPHWs) and } \\
\text { accredited social } \\
\text { health activist } \\
\text { (ASHA) workers }\end{array}$ & $\begin{array}{l}\text { Range of primary care services } \\
\text { delivered by three types of CHWs } \\
\text { at the sub-centre health facility } \\
\text { level; study compares having } \\
\text { one ANM with two ANMs. }\end{array}$ & $\begin{array}{l}\text { Costing and cost- } \\
\text { effectiveness study } \\
\text { from a health system } \\
\text { perspective }\end{array}$ & Unclear & Yes & Yes & No & No & $\begin{array}{l}\text { Hiring a second ANM at the } \\
\text { sub-centre level is very } \\
\text { cost-effective given the } \\
\text { incremental cost per unit } \\
\text { increase in ANC coverage. }\end{array}$ \\
\hline
\end{tabular}


volunteers, opportunity cost or shadow price) and recurrent expenses such as materials, supplies, transport and supervision, although the individual unit quantities and costs were rarely reported. Eighteen studies included the value of capital items such as vehicles and equipment although the specifics were not always mentioned [11-13, $15,18,19,21,27-37]$. Overhead costs were included in 17 studies [11, 13, 15, 18, 20-22, 27, 28, 30-37], for example, for $\mathrm{TB}$, on the basis of the proportion of total health facility visits or inpatient days for which TB accounted. Three of the 13 studies used a flat rate of $15 \%$ or $30 \%[13,30,32]$.

Patient costs were included in 11 of the studies [12, 15, 18-22, 29-31, 37], including time for visits and hospitalization as well as transport, medicines, food and other expenses.

The studies relied on a wide range of data sources, including budget and expenditure files from health facilities, hospitals, districts, government price lists, patient questionnaires, literature, time sheets, payroll records, ministries of health and finance and project accounts.

Many of the studies did not estimate costs over a future time period; therefore, a discount rate was unnecessary. Four studies discounted costs at 3\% [11, 19, $33,38]$ and two others at $5 \%[27,30]$. The costing year ranged from 1996 to 2011, and all but one [23] reported in US dollars.

Studies reported costs in a number of different ways, including weighted mean costs [15], average programme costs [15], average costs $[12,13,27,39,40]$, cost per activity $[20,21]$, cost per patient managed or treated $[18,22,41]$, cost per child $[16,17,23,33,35,36]$, cost per inhabitant covered [32] or per capita [24] and total annual costs [19, 29, 31-34, 37]. Two studies estimated potential cost savings, from reduced facility visits [17] and reductions in non-fatal cardiovascular events [42], and another mentioned that the CHW intervention (TB care) may lead to a reduction in multi-drug-resistant $\mathrm{TB}$ and the related drug costs [14].

\section{Outcomes}

Various outcome measures reported by included studies are presented in Table 4. As for costs, many of the studies did not estimate benefits over a future time period; therefore, a discount rate was unnecessary. Two studies mentioned discounting future benefits at $3 \%[19,31]$ and another at 5\% [30] in the base case or standard analysis. Data sources for outcomes included randomized trials, monitoring and evaluation systems, organizational and government offices, demographic surveillance systems and patient treatment registers. One study used assumptions about yearly incidence and disease progression [23].
Table 4 Outcome measures

\begin{tabular}{|c|c|}
\hline \multicolumn{2}{|c|}{ Outcomes at the level of health status and well-being } \\
\hline \multirow[t]{4}{*}{ TB studies } & Sputum smear results \\
\hline & TB cure rate \\
\hline & Treatment completion rate \\
\hline & Treatment success rate \\
\hline Malaria studies & Incidence of malaria and anaemia \\
\hline \multirow[t]{5}{*}{ MNCH studies } & Neonatal mortality \\
\hline & Deaths averted \\
\hline & DALYs averted \\
\hline & $\begin{array}{l}\text { Incidence of acute PPH and severe } \\
\text { PPH cases }\end{array}$ \\
\hline & Anaemia cases averted \\
\hline \multirow[t]{2}{*}{ Other studies } & Systolic blood pressure \\
\hline & $\begin{array}{l}\text { Presence/absence of depression } \\
\text { or anxiety }\end{array}$ \\
\hline \multicolumn{2}{|c|}{ Intermediate outcomes: patient level } \\
\hline \multicolumn{2}{|c|}{ Number of patients registered or who received treatment } \\
\hline \multicolumn{2}{|c|}{ Increased patient enrollment } \\
\hline \multicolumn{2}{|c|}{ Number of patients counselled } \\
\hline \multicolumn{2}{|c|}{ Number of patient visits made } \\
\hline \multicolumn{2}{|c|}{ Number of referrals made } \\
\hline \multicolumn{2}{|c|}{ Proportion of cases appropriately diagnosed and treated } \\
\hline \multicolumn{2}{|c|}{ Number of doses taken by patients } \\
\hline \multicolumn{2}{|c|}{ Weeks of exclusive breastfeeding } \\
\hline \multicolumn{2}{|c|}{ Couple years of protection } \\
\hline \multicolumn{2}{|c|}{ Intermediate outcome: health worker level } \\
\hline Professional hea & gained \\
\hline
\end{tabular}

\section{Cost-effectiveness}

Where assessed, the studies presented the cost-effectiveness of CHWs in terms of cost per visit [28], cost per patient or presumptive case successfully treated $[14,15,20,41]$, cost per patient cured $[18,21]$, cost per patient completing treatment $[18,37]$, cost per disability-adjusted life year (DALY) averted [23, 30, 37, 38, 40], cost per malaria case averted [29], cost per malaria case correctly diagnosed and treated [13], cost per case recovered [12], cost per couple-year of protection [26], cost per life year saved [11,39] and cost per death averted [37]. Three studies reported the cost-effectiveness ratio comparing two interventions $[19,31,35]$.

\section{Overall assessment of cost and cost-effectiveness by dis- ease area}

For ease of reporting, both costing and cost-effectiveness findings are presented below. For a summary of all results by disease area, see Table 3 . 


\section{RMNCH}

Findings about the costs and cost-effectiveness of CHWs for a number of different $\mathrm{RMNCH}$ conditions and for different types of activities are generally positive. For maternal health, misoprostol prevention and treatment provided by village health workers were found to be more cost-effective than standard care (although standard care was not defined). Treatment was also found to be significantly more cost-effective than prevention in a simulation setting (looking at cost per life saved only) [39, 40]. With regard to family planning, Chin-Quee et al. found the cost of adding an intervention to deliver injectable contraceptives to an existing community-based distribution package to be "low" [26]. In the area of neonatal health, women groups facilitated by lay health workers (LHWs) and trained traditional birth attendants (TBAs) were found to be cost-effective ways of reducing neonatal deaths compared to current practice $[11,38]$. The use of local women trained as peer supporters to individually counsel women about exclusive breast feeding was found to be implementable in sub-Saharan Africa at a "sustainable cost" [28].

For child health, CHWs were found to be costeffective for reducing under-five mortality and resulted in cost savings compared to the facility-based alternative for under-five child growth monitoring, counselling, curative care treatment and free-of-charge medicines as well as home visits as needed [16, 17, 19]. A study from India found implementation of integrated management of neonatal and child illnesses by CHWs imposed additional costs to the health system, but could not draw a conclusion about cost-effectiveness [36], while a study from Bangladesh on community management of severe acute malnutrition found the practice to be more costeffective than facility-based inpatient treatment [37]. Two reviews of literature on the use of lay and community health workers in vaccination programmes by Corluka et al. [43] and Pegurri et al. [44] found these workers to be more cost-effective options than the comparator which did not include LHWs, including in an outreach setting.

\section{$T B$}

Studies from Brazil [21], Ethiopia [15], Malawi [18], South Africa [14, 22] and Uganda [20] found that using CHWs during the non-hospitalized phase of TB treatment is a cost-effective alternative to facility-based treatment. CHWs were found to reduce the cost per patient successfully treated and cured anywhere from 40\% to $74 \%$ compared with facility-based provision. Okello et al. point out the importance of proper training and supervision in achieving success [20].

\section{Malaria}

Results are limited but generally positive from studies in favour of the cost-effective use of CHWs for malaria programmes compared with regular care. Studies found the delivery of intermittent preventive treatment (IPT) of malaria for children by village health workers was less costly then delivery by nurses in outpatient departments or immunization outreach [29, 33]; community-based delivery of sulfadoxine-pyrimethamine (SP) during pregnancy increased access, improved adherence to IPT and was cost-effective according to World Bank criteria [31]; and home management of uncomplicated malaria by CHWs was $36 \%$ more cost-effective than the standard care in health facilities [13]. The use of pre-referral artesunate for the treatment of childhood malaria by $\mathrm{CHWs}$ was found to be a cost-effective (according to WHO guidelines comparing cost per DALY averted with gross domestic product (GDP) per capita), life-saving intervention with potential application in rural African settings where $\mathrm{CHW}$ programmes are already in place (comparing cost per DALY averted with GDP per capita, according to WHO guidelines) [23]. A study from Zambia looking at active and passive case detection by $\mathrm{CHWs}$ including testing and treatment concluded that the programme may be cost-effective when community participation in regular testing reached certain levels [24]. Additionally, based on results from two villages, Onwujekwe et al. concluded that starting up a CHW programme for malaria control nationwide in Nigeria is potentially "cost-effective", although no comparator or benchmark was given [41].

\section{Other health priority areas}

For wider primary care, studies have found that CHWs increased the coverage and equity of service delivery at low cost compared with alternatives, that using CHWs can be less costly than other community-based programmes and that comprehensive $\mathrm{CHW}$ subsystems can be deployed across sub-Saharan Africa at a modest cost compared with the project costs of a primary healthcare system $[9,32,34]$. A study from India further found that adding an additional primary care community-based health worker to the lowest level of the health facility was cost-effective, though results were only be measured in terms of cost of increasing ANC coverage [35].

Findings related to the cost-effectiveness of $\mathrm{CHWs}$ for other disease areas were limited but generally favourable to the use of CHWs to control hypertension (although in one study best results were achieved when combined with general practitioner training as well) [30, 42] and for interpersonal therapy and case management of patients with mental disorders [12]. Additionally, an mhealth intervention implemented by $\mathrm{CHWs}$ on a variety of healthcare topics including treatment adherence 
monitoring, appointment reminders and emergency care resulted in monetary as well as time savings [25].

Overall, the results of this analysis are in line with findings from the review/discussion papers included in this study. Perry et al. found that where the costeffectiveness of CHW-provided interventions is compared with that of facility-based interventions, the CHW-provided interventions are generally found to be more cost-effective [45], and Walker et al. found CHWs working in primary healthcare, vaccination and TB control programmes increase the coverage and equity of service delivery at low cost compared with alternative modes of service organization [9].

\section{Discussion}

This review has found promising evidence in favour of the cost-effectiveness of CHWs as compared with standard practice or alternative delivery models or when comparing cost-effectiveness findings with a benchmark such as GDP per capita, although results should be interpreted with the understanding of both minor and major methodological challenges.

\section{Methodological issues and limitations}

This analysis of 36 articles and reviews from the period January 2003 to July 2015 has revealed the variety of methodological approaches used to assess the costs and cost-effectiveness of CHWs, which limits both comparability and generalizability. Additionally, many articles did not provide sufficient details about study design or methodological assumptions, such as time horizon and study perspective, data quality and sources, limiting their usefulness. However, these were often earlier articles and may reflect the newness of economic evaluation methods. Many studies also failed to recognize the limitations of their data or question the quality. A mixed methods approach to costing and cost-effectiveness studies could enhance insight on the functioning and communityperceived value of CHWs and therefore add much-needed depth to a costing or cost-effectiveness study.

The issue of perspective has emerged as an important methodological challenge in this review: approximately half the studies in this review took a provider or health service perspective. Because of the nature of CHWs, taken from and embedded in the community, as well as health economics methodologies developed to date, current ways of assessing costs and benefits of these programmes (including use of the provider or government perspective) fail to capture many of the important societal costs and benefits associated with CHWs, such as social capital and trust as identified by Walker et al. [9] and improved relationships between patients and care providers. These aspects may have fallen outside the purview of economic evaluations to date because they are not monetizable, but leaving them out means we are failing to capture the true costs and benefits of CHWs in costing studies and economic evaluations. On the issue of perspective, in some cases, CHWs might reduce patient costs (for example, for TB, where patients receiving treatment in the community no longer have to travel to health facilities), making it important to take a wider perspective. And while our review did not touch on financial versus economic costs (how much the project or programme actually pays compared with the overall cost of the project or programme), this is a closely related issue. Additionally, as CHWs often operate as part of larger healthcare teams, it would be desirable to assess their cost-effectiveness as part of the broader health system in which they operate rather than as stand-alone programmes.

Finally, given the large number of $\mathrm{CHW}$ programmes, many operating already for decades, this review also reveals that the cost and cost-effectiveness of many $\mathrm{CHW}$ programmes have not been extensively and systematically assessed. As CHWs grow in popularity and are incorporated in human resources for health policies and plans in different countries, the need for well-designed and conducted costing and cost-effectiveness studies becomes particularly important.

\section{Cost and cost-effectiveness issues}

This review has found evidence supporting the costeffective use of CHWs, particularly in the area of TB; there are also studies supporting the cost-effective use of $\mathrm{CHWs}$ in the areas of $\mathrm{RMNCH}$, malaria and other disease areas, although their methodology and quality of evidence are less strong. However, even where there is evidence suggesting a better cost-effectiveness of CHWs compared to other service delivery models, results should be interpreted with caution. The reviewed studies used very different methodologies; they compared CHWs to different cadres of health workers, and sometimes, there was no comparator. Furthermore, the studies in this review included and excluded different costs: for example, often they did not include the important and sizeable training and supervision or recruitment and retention costs related to CHWs. Additionally, volunteer time was valued differently in different studies and sometimes excluded altogether. Effectiveness of $\mathrm{CHWs}$ was also measured differently in different studies.

On the issue of comparability and generalizability, one fundamental challenge with comparing or generalizing CHW costing and cost-effectiveness findings is the varying nature of CHWs themselves. Although often lumped together, there is a wide typology of $\mathrm{CHW}$ models worldwide, with training and competencies varying enormously. Studies should include more details about the type of $\mathrm{CHW}$ being assessed and their context, and these 
differences should be taken into consideration when attempting to compare results [46].

The majority of articles reviewed documented CHW involvement in short-term or limited duration TB, malaria and $\mathrm{RMNCH}$ programmes, reflecting the use of CHWs in some countries for specific health areas or conditions. However, evidence is more limited about the costs or cost-effectiveness of CHWs who take on responsibilities across a wider range of disease areas or conditions and on the long-term cost-effectiveness and systemic implications of these programmes. A study by Alam et al. on maternal health from Bangladesh found retention of CHWs to be a problem, and the cost associated with dropout was significant, leading the programme to be less sustainable [27]. Cost-effectiveness analyses are often presented as snapshots of a certain short period of time, while longer term issues of retention and sustainability should be considered as well.

Further mixed method research is needed to better understand why CHWs are sometimes cost-effective and sometimes not and if there are fundamental aspects of different health areas that lend themselves to a costeffective use of CHWs. For example, it could by hypothesized that CHWs are cost-effective in the area of TB because the activities performed are limited and easy to standardize, whereas CHW activities in the area of $\mathrm{RMNCH}$ may be more varied. It would be interesting to examine CHW cost-effectiveness on the different components of RMNCH separately (for example, antenatal care and deliveries separately) and analyse cost and costeffectiveness differences between these activities. Additionally, research is needed to understand the impact of the task sharing on efficiency, costs and cost-effectiveness of both the programme from which the tasks were split, the CHW and the system as a whole [47].

Besides the limitations of the reviewed studies, limitations of this review itself should be taken into consideration. Publication bias is a potential issue; some relevant studies may have been missed if they were not identified by the larger search from which these results were taken or the supplementary PubMed search, and we did not consider grey literature. We have also not specifically evaluated the quality of the reviewed studies, though the review points out methodological shortcomings of the reviewed studies as a whole.

\section{Conclusions and policy implications}

This literature review suggests that using CHWs in health programmes can be a cost-effective intervention in some settings, particularly for TB, with less strong evidence but promising indications of cost-effectiveness in $\mathrm{RMNCH}$ and malaria. These findings may relate to the fact that some areas have been evaluated less (and less rigorously) than others, rather than reflecting an actual difference in cost-effectiveness in the various service delivery areas or interventions.

Notwithstanding the caveats mentioned above about the heterogeneity of the studies and methodological weaknesses, this review shows that CHWs programmes have potential to represent good value for money for governments and donors for delivery of essential health services in LMIC. In developing or scaling up $\mathrm{CHW}$ programmes, however, more attention needs to be given to understanding costs and cost-effectiveness from both a government and societal perspective and to integrating community health workers in national healthcare systems in terms of employment, supervision, support and career development $[48,49]$.

\section{Abbreviations}

CHW: Community health worker; DALY: Disability-adjusted life year; GDP: Gross domestic product; LHW: Lay health worker; LMIC: Low- and middle-income country; RMNCH: Reproductive maternal, newborn and child health; TB: Tuberculosis; TBA: Traditional birth attendant.

\section{Competing interests}

The authors declare that they have no competing interests.

\section{Authors' contributions}

KV developed the data extraction matrix, read and analysed articles and drafted the report on which this article is based. MK formulated the search strategy, selected, read and analysed articles and provided feedback to the drafts. SW provided feedback on all drafts, particularly with regard to the discussion. MD read and analysed articles, provided feedback to the drafts and contributed to the discussion. All authors read and approved the final manuscript.

\section{Authors' information}

KV (MSc, MPP) is a health economist at the Royal Tropical Institute (KIT) who has costed CHW programmes in Indonesia and Namibia. MK (MSc) is a Researcher in Health Systems at KIT. She recently published a systematic review in Health Policy and Planning on intervention design factors that influence performance of CHWs in low- and middle-income countries. SW holds a PhD in Health Economics and is a Professor at Queen Margaret University. MD holds a PhD, MSc and MPH and is a Senior Advisor on Human Resources for Health at KIT.

\section{Acknowledgements}

This study was carried out as part of a project funded by the UK Department for International Development (DFID) and managed by the Global Health Workforce Alliance (a partnership hosted by the World Health Organization) on assessing the cost-effectiveness of CHW programmes implemented at scale. It was jointly implemented by Queen Margaret University (QMU), Liverpool School of Tropical Medicine (LSTM) and the Royal Tropical Institute (KIT).

The authors acknowledge the comments on earlier drafts by the Global Health Workforce Alliance Secretariat and by the members of the research committee that provided technical guidance and quality assurance over the project: Giorgio Cometto (Global Health Workforce Alliance, WHO), Neil Squires (DFID), Taghreed Adam (Alliance for Health Policy and Systems Research, WHO), Franco Pagnoni (WHO) and Chutima Suraratdecha (United States Agency for International Development).

The search protocol was used with permission from REACHOUT (http:// www.reachoutconsortium.org), an ongoing research consortium funded by the European Commission's FP7 Framework for Health focused on maximizing the equity, effectiveness and efficiency of close-to-community services. REACHOUT is implemented by LSTM and KIT together with partners in Bangladesh, Ethiopia, Indonesia, Kenya, Malawi and Mozambique. REACHOUT is funded by the European Union Seventh Framework Programme ([FP7/2007-2013] [FP7/2007-2011]) under grant agreement number 306090. 


\section{Author details}

${ }^{1}$ Royal Tropical Institute (KIT), P.O. Box 95001, 1090 HA Amsterdam, The Netherlands. ${ }^{2}$ Queen Margaret University, Edinburgh, Scotland.

\section{Received: 6 January 2015 Accepted: 18 August 2015} Published online: 01 September 2015

\section{References}

1. Haines A, Sanders D, Lehmann U, Rowe AK, Lawn JE, Jan S, et al. Achieving child survival goals: potential contribution of community health workers. Lancet. 2007;369:2121-31.

2. Kok MC, Dieleman M, Taegtmeyer M, Broerse JE, Kane SS, Ormel H, et al. Which intervention design factors influence performance of community health workers in low- and middle-income countries? A systematic review. Health Policy Plan. 2014;1-21 doi:10.1093/heapol/czu126.

3. Perry HB, Zulliger R, Rogers MM. Community health workers in low-, middle-, and high-income countries: an overview of their history, recent evolution, and current effectiveness. Annu Rev Public Health. 2014;35:399-421.

4. Schneider H, Lehmann U. Lay health workers and HIV programmes: implications for health systems. AIDS Care. 2010;22 Suppl 1:60-7.

5. Glenton C, Scheel IB, Lewin S, Swingler GH. Can lay health workers increase the uptake of childhood immunisation? Systematic review and typology. Trop Med Int Health. 2011;16:1044-53.

6. Lewin S, Munabi-Babigumira S, Glenton C, Daniels K, Bosch-Capblanch X, van Wyk BE, et al. Lay health workers in primary and community health care for maternal and child health and the management of infectious diseases. Cochrane Database Syst Rev (Online). 2010;3, CD004015.

7. van Ginneken N, Tharyan P, Lewin S, Rao GN, Meera SM, Pian J, et al. Non-specialist health worker interventions for the care of mental, neurological and substance-abuse disorders in low-and middle-income countries. Cochrane Database Syst Rev. 2013;11, CD009149.

8. Lehmann U, Sanders D. Community health workers: What do we know about them? The state of the evidence on programmes, activities, costs and impact on health outcomes of using community health workers. World Health Organ. 2007.

9. Walker DG, Jan S. How do we determine whether community health workers are cost-effective? Some core methodological issues. J Community Health. 2005:30:221-9.

10. Torrance GW, Drummond MF. Methods for the economic evaluation of health care programs. Oxford: Oxford University Press; 2005.

11. Borghi J, Thapa B, Osrin D, Jan S, Morrison J, Tamang S, et al. Economic assessment of a women's group intervention to improve birth outcomes in rural Nepal. Lancet. 2005;366:1882-4.

12. Buttorff C, Hock RS, Weiss HA, Naik S, Araya R, Kirkwood BR, et al. Economic evaluation of a task-shifting intervention for common mental disorders in India. Evaluation economique d'une intervention de transfert de taches dans le cadre du traitement des troubles mentaux communs en Inde. 2012;90:813-21.

13. Chanda P, Hamainza B, Moonga HB, Chalwe V, Banda P, Pagnoni F. Relative costs and effectiveness of treating uncomplicated malaria in two rural districts in Zambia: implications for nationwide scale-up of home-based management. Malar J. 2011;10:159.

14. Clarke M, Dick J, Bogg L. Cost-effectiveness analysis of an alternative tuberculosis management strategy for permanent farm dwellers in South Africa amidst health service contraction. Scand J Public Health. 2006:34:83-91.

15. Datiko DG, Lindtjørn B. Cost and cost-effectiveness of smear-positive tuberculosis treatment by Health Extension Workers in Southern Ethiopia: a community randomized trial. PLoS One. 2010;5(2):e9158.

16. Fiedler JL. A Cost Analysis of the Honduras Community-Based, Integrated Child Care Program (Atención Integral a la Niñez-Comunitaria, AIN-C). In World Bank HNP Discussion Paper. Washington, DC: World Bank; 2003.

17. Fiedler JL, Villalobos CA, De Mattos AC. An activity-based cost analysis of the Honduras community-based, integrated child care (AIN-C) programme. Health Policy Plan. 2008;23:408-27.

18. Floyd K, Skeva J, Nyirenda T, Gausi F, Salaniponi F. Cost and costeffectiveness of increased community and primary care facility involvement in tuberculosis care in Lilongwe District, Malawi. Int J Tuberc Lung Dis. 2003;7:S29-37.
19. Nonvignon J, Chinbuah MA, Gyapong M, Abbey M, Awini E, Gyapong JO, et al. Is home management of fevers a cost-effective way of reducing under-five mortality in Africa? The case of a rural Ghanaian District. Trop Med Int Health. 2012;17:951-7.

20. Okello D, Floyd K, Adatu F, Odeke R, Gargioni G. Cost and cost-effectiveness of community-based care for tuberculosis patients in rural Uganda. Int $J$ Tuberc Lung Dis. 2003;7:S72-9.

21. Prado TN, Wada N, Guidoni LM, Golub JE, Dietze R, Maciel EL. Costeffectiveness of community health worker versus home-based guardians for directly observed treatment of tuberculosis in Vitoria, Espirito Santo State, Brazil. Cad Saude Publica. 2011;27:944-52.

22. Sinanovic E, Floyd K, Dudley L, Azevedo V, Grant R, Maher D. Cost and cost-effectiveness of community-based care for tuberculosis in Cape Town, South Africa. Int J Tuberc Lung Dis. 2003;7:S56-62.

23. Tozan $Y$, Klein EY, Darley $S$, Panicker $R$, Laxminarayan R, Breman JG Prereferral rectal artesunate for treatment of severe childhood malaria: a cost-effectiveness analysis. Lancet. 2010;376:1910-5.

24. Hamainza B, Moonga H, Sikaala CH, Kamuliwo M, Bennett A, Eisele TP, et al. Monitoring, characterization and control of chronic, symptomatic malaria infections in rural Zambia through monthly household visits by paid community health workers. Malar J. 2014;13:10.1186.

25. Mahmud N, Rodriguez J, Nesbit J. A text message-based intervention to bridge the healthcare communication gap in the rural developing world Technol Health Care. 2010;18:137-44.

26. Chin-Quee D, Bratt J, Malkin M, Nduna MM, Otterness C, Jumbe L, et al. Building on safety, feasibility, and acceptability: the impact and cost of community health worker provision of injectable contraception. Global Health: Science and Practice. 2013:1:316-27.

27. Alam K, Khan JA, Walker DG. Impact of dropout of female volunteer community health workers: an exploration in Dhaka urban slums. BMC Health Serv Res. 2012;12:260.

28. Chola L, Nkonki L, Kankasa C, Nankunda J, Tumwine J, Tylleskar T, et al. Cost of individual peer counselling for the promotion of exclusive breastfeeding in Uganda. Cost Effectiveness \& Resource Allocation. 2011;9:9p.

29. Conteh L, Patouillard E, Kweku M, Legood R, Greenwood B, Chandramohan D. Cost effectiveness of seasonal intermittent preventive treatment using amodiaquine \& artesunate or sulphadoxine-pyrimethamine in Ghanaian children. PLoS One. 2010:5:e12223.

30. Jafar TH, Islam M, Bux R, Poulter N, Hatcher J, Chaturvedi N, et al. Costeffectiveness of community-based strategies for blood pressure control in a low-income developing country: findings from a cluster-randomized, factorial-controlled trial. Circulation. 2011;124:1615-25.

31. Mbonye AK, Hansen KS, Bygbjerg IC, Magnussen P. Intermittent preventive treatment of malaria in pregnancy: the incremental cost-effectiveness of a new delivery system in Uganda. Trans R Soc Trop Med Hyg. 2008;102:685-93.

32. McCord GC, Liu A, Singh P. Deployment of community health workers across rural sub-Saharan Africa: financial considerations and operational assumptions. Bull World Health Organ. 2013;91:244-253B.

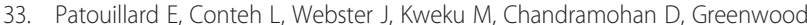
B. Coverage, adherence and costs of intermittent preventive treatment of malaria in children employing different delivery strategies in Jasikan, Ghana. PLoS One. 2011;6:e24871.

34. Bowser D, Okunogbe A, Oliveras E, Subramanian L, Morrill T. A costeffectiveness analysis of community health workers in Mozambique. J Prim Care Community Health. 2015;2150131915579653. doi:10.1177/ 2150131915579653.

35. Prinja S, Jeet G, Verma R, Kumar D, Bahuguna P, Kaur M, et al. Economic analysis of delivering primary health care services through community health workers in 3 North Indian states. PLoS One. 2014;9, e91781.

36. Prinja S, Mazumder S, Taneja S, Bahuguna P, Bhandari N, Mohan P, et al Cost of delivering child health care through community level health workers: how much extra does IMNCI program cost? J Trop Pediatr. 2013:59:489-95.

37. Puett C, Sadler K, Alderman H, Coates J, Fiedler JL, Myatt M. Costeffectiveness of the community-based management of severe acute malnutrition by community health workers in southern Bangladesh. Health Policy Plan. 2013;28:386-99.

38. Sabin LL, Knapp AB, MacLeod WB, Phiri-Mazala G, Kasimba J, Hamer DH, et al. Costs and cost-effectiveness of training traditional birth attendants to reduce neonatal mortality in the Lufwanyama Neonatal Survival study (LUNESP). PLoS One. 2012;7, e35560. 
39. Sutherland T, Bishai DM. Cost-effectiveness of misoprostol and prenatal iron supplementation as maternal mortality interventions in home births in rural India. Int J Gynaecol Obstet. 2009;104:189-93.

40. Sutherland T, Meyer C, Bishai DM, Geller S, Miller S. Community-based distribution of misoprostol for treatment or prevention of postpartum hemorrhage: cost-effectiveness, mortality, and morbidity reduction analysis. Int J Gynaecol Obstet. 2010;108:289-94.

41. Onwujekwe O, Uzochukwu B, Ojukwu J, Dike N, Shu E. Feasibility of a community health worker strategy for providing near and appropriate treatment of malaria in southeast Nigeria: an analysis of activities, costs and outcomes. Acta Trop. 2007;101:95-105.

42. Gaziano TA, Bertram M, Tollman SM, Hofman KJ. Hypertension education and adherence in South Africa: a cost-effectiveness analysis of community health workers. BMC Public Health. 2014;14:240.

43. Corluka A, Walker DG, Lewin S, Glenton C, Scheel IB. Are vaccination programmes delivered by lay health workers cost-effective? A systematic review. Hum Resour Health. 2009:7:81.

44. Pegurri E, Fox-Rushby JA, Damian W. The effects and costs of expanding the coverage of immunisation services in developing countries: a systematic literature review. Vaccine. 2005;23:1624-35.

45. Perry $H$, Zulliger $R$. How effective are community health workers? An overview of current evidence with recommendations for strengthening community health worker programs to accelerate progress in achieving the health-related Millennium Development Goals, Johns Hopkins Bloomberg School of Public Health. 2012

46. Kok MC, Kane SS, Tulloch O, Ormel H, Theobald S, Dieleman M, et al. How does context influence performance of community health workers in low-and middle-income countries? Evidence from the literature. Health Res Policy Syst. 2015;13:13.

47. Lehmann U, Van Damme W, Barten F, Sanders D. Task shifting: the answer to the human resources crisis in Africa? Hum Resour Health. 2009;7:49.

48. Tulenko K, Møgedal S, Afzal MM, Frymus D, Oshin A, Pate M, et al. Community health workers for universal health-care coverage: from fragmentation to synergy. Bull World Health Organ. 2013;91:847-52.

49. Singh P, Sachs JD. 1 million community health workers in sub-Saharan Africa by 2015. The Lancet. 2013;382:363-5.

\section{Submit your next manuscript to BioMed Central and take full advantage of:}

- Convenient online submission

- Thorough peer review

- No space constraints or color figure charges

- Immediate publication on acceptance

- Inclusion in PubMed, CAS, Scopus and Google Scholar

- Research which is freely available for redistribution 